\title{
A Study on Angiographic profile of Acute Coronary Syndrome in Smokers
}

\author{
Hemasundar Korrapati ${ }^{\circledR 1}$, B.V. Narayana Reddy ${ }^{\circledR 1}$, Supraja Chegireddy ${ }^{2} 2$ \\ ${ }^{1}$ Assistant Professor, Department of Cardiology, Katuri Medical College \& Hospital, Guntur, Andhra Pradesh, India, ${ }^{2}$ Assistant Professor, Department of Radio Diagnosis, \\ Katuri Medical College \& Hospital, Guntur, Andhra Pradesh, India.
}

\section{Abstract}

Background: Coronary artery disease is a devastating disease precisely because an otherwise healthy person in the prime of life may die or become disabled without warning. The objectives of the study were to study the clinical profile, risk factors prevalence, angiographic distribution and severity of coronary artery stenosis in acute coronary syndrome (ACS) patients admitted in Cardiology Department of Cardiology Katuri Medical College \& Hospital, Guntur. Subjects and Methods: A total of 208 patients of ACS were analyzed for various risk factors, angiographic patterns and severity of coronary artery disease in smokers vs non-smokers at Katuri Medical College, Andhra Pradesh. Results: Study group consisted of 208 subjects, of which 108(51.9\%) subjects were smokers including all forms of tobacco use and 100 (48.1 Out of 108 study subjects in the smokers group, family history of CAD was present in $21(19.4 \%)$ subjects. Killip class is not applicable to 13 (12\%) study groups as they presented with Unstable Angina with ECG changes. Killip class 1 was most common presentation (67.6\%) in smokers. 28 patients (25.9\%) had LV dysfunction with EF $<50 \%$ by echocardiography. 80 patients $(74.1 \%)$ had normal LV function. The mean EF was $55.56+/-10.16 \%$. The median EF was 56.5\%. LAD was type 3 in 100 (92.6\%) patients and type 4 in $8(7.4 \%)$ patients out of 108 study subjects. LAD type 3 was statistically significant with $\mathrm{P}$ value $<0.05$ when compared with LAD type 4 . No statistically significant difference was seen with respect to the Normal coronary arteries as CAG diagnosis between smokers and non-smokers ( $6.7 \%$ versus $8 \%$, $p>0.1$, Not significant). Conclusion: Smokers were predominantly male and around 3 years younger than non-smokers. Diabetes mellitus and hypertension were less common among smokers and single-vessel disease was the more common angiographic finding for smokers as compared to 3-vessel disease for non-smokers. ST-segment elevation myocardial infarction in smokers despite younger age and the low atherosclerotic risk profile, in our region, emphasize the need for nicotine addiction management and smoking cessation campaigns at large and for pre-discharge counseling.

Keywords: Acute coronary syndrome, Left ventricles, ECG, Angiogram

Corresponding Author: B.V. Narayana Reddy, Assistant Professor, Department of Cardiology, Katuri Medical College \& Hospital, Guntur, Andhra Pradesh, India.

E-mail: jaffarshaik4407@gmail.com

Received: 11 March 2020

Revised: 14 April 2020

Accepted: 5 May 2020

Published: 27 May 2020

\section{Introduction}

Cardiovascular disease (CVD) is the leading cause of death globally. ${ }^{[1]}$ Cigarette smoking is a major modifiable risk factor for CVD, including coronary artery disease (CAD), stroke, peripheral vascular disease, and congestive heart failure. ${ }^{[2,3]}$ The relationship between cigarette smoking and many established risk factors for CVD have been studied. Cigarette smoking is associated with higher levels of serum cholesterol, coronary vasomotor reactivity, platelet aggregation, and a prothrombotic state. ${ }^{[4-7]}$ By the year 2030, cigarette smoking will contribute to 10 million deaths per year, $70 \%$ of them in lowand middle- income countries. ${ }^{[8]}$ There are multiple and interacting determinants that affect smoking. ${ }^{[9]}$ These are physiological factors (nicotine addiction), personal characteristics (demographics, personality, education, and information), cognition and skills, environment (social, cultural, economic and political) and other concomitant habits (drinking alcohol, coffee etc). ${ }^{[10]}$

Cigarette smoking is generally known as an important risk factor for pathogenesis of coronary artery disease (CAD), as well as prognosis. ${ }^{[1-8]}$ Smoking cessation is recommended by international guidelines as one of crucial measurements for secondary prevention regardless of revascularization. ${ }^{[9-12]}$

Angiographic assessment is a vital step in the planning management and treatment for patients with cardiovascular diseases. Local data regarding clinical and angiographic characteristics of smoker patients is lacking. This study was planned to assess the differences in the clinical characteristics, angio- 
graphic characteristics, and in-hospital outcomes of smokers and non-smokers after primary percutaneous coronary intervention (PCI) at a tertiary care hospital.

Therefore our aim of our study was to determine the angiographic profile in acute coronary syndrome of smokers.

\section{Subjects and Methods}

\section{Inclusion criteria}

1. Patients with first episode of ACS (Unstable Angina with ECG changes, NSTEMI,STEMI) attending the ICCU, Department of Cardiology, Katuri Medical College \& Hospital.

2. Different types of ACS were diagnosed according to ECG criteria and Troponin $T$ positivity.

3. Both Smokers and non Smokers were included in the study group.

4. Smoking history (all forms-tobacco chewing / khaini / beedi / tambaku / cigars.

5. Troponin positivity (qualitative for NSTEMI differentiating from USA with ECG changes.

6. Coronary angiogram was done after 5 days of Heparin theraphy in acute coronary syndrome

\section{Exclusion criteria}

1. Age $<18$ years $/>80$ years

2. Patients with recurrent episode of ACS and Cardiogenic shock.

3. Patients with Valvular heart diseases/ cardiomyopathies/ pericardial diseases/ conduction diseases other than ischemia,

4. Contradications to $\mathrm{CAG}$ (pts with serum creatinine $>1.5 \mathrm{mg} / \mathrm{dl}$,lack of consent for CAG) and prior coronary angiogram report.

5. Unstable Angina without ECG changes

The various baseline characteristics studied include, age and sex of the patients, presentation of the Acute coronary syndrome (Unstable angina with ECG changes versus acute myocardial infarction (acute STEMI+acute NSTEMI)

\section{D Echocardiography:}

All the echocardiograms were done on a IE 133 phillips echocardiography machine. The echocardiography parameters evaluated included:

- Ejection fraction as impaired LV function $(\mathrm{EF}<50 \%$ or normal (EF $>/ 50 \%)$.

- Coronary angiograms were performed with SIEMENS CATH LAB on all the patients within 5 to 7 days after ACS /Primary PTCA done in the case of eligible patients. Informed consent was taken from all the patients.
- Coronary angiograms were compared between smokers and non smokers with respect to Normal coronary arteries, Single Vessel disease (SVD), Double Vessel disease (DVD), Triple Vessel disease (TVD), Left main coronary artery (LMCA) involvement, Proximal LAD involvement.

- Coronary angiograms were analyzed for the following characteristics in the smokers group.

\section{Number of vessels involved}

\section{Severity of the lesion}

a. Based on the percentage diameter stenosis of the involved artery compared to the normal reference segment.

b. Lesions are classified as severe if $70 \%$ or more diameter stenosis is observed in the LAD, LCX, RCA and more than or equal to $50 \%$ diameter stenosis in the LMCA.

\section{Location of the lesion in the involved artery}

- LAD: ostial, proximal, middle or distal/ its major branch

- LCX: ostial, proximal, middle or distal / its major branch

- RCA: ostial, proximal, middle or distal / its major branch

\section{Length of the lesion: measured shoulder to shoulder in an} nonfore shortened view

- Discrete: lesion length less than $10 \mathrm{~mm}$

- Tubular: lesion length 10 to $20 \mathrm{~mm}$

- Diffuse: lesion length of at least $20 \mathrm{~mm}$

Present study defined, SVD $>/=40 \%$ diameter stenosis in one epicardial coronary artery (diameter $>2.25 \mathrm{~mm}$ ) with respect to reference vessel diameter.

DVD defined as $>/=40 \%$ diameter stenosis in two epicardial coronary arteries (diameter $>2.25 \mathrm{~mm}$ ) with respect to reference vessel diameter.

TVD defined as $>/=40 \%$ diameter stenosis in three epicardial coronaries (diameter $>2.25 \mathrm{~mm}$ ) with respect to reference vessel diameter.

LMCA involvement defined with > or equal to $30 \%$ diameter narrowing.

Angiographic profile was analyzed with respect to each of the baseline characters described above in the smokers group.

\section{Statistical analysis}

Statistical Analysis was done using SPSS software. Mean, median, standard deviation and Chi Squares were calculated wherever applicable. $\mathrm{P}$ value of $\mathrm{p}<0.05$ was considered statistically significant.

Results

Age and Sex distribution in smokers 


\begin{tabular}{lll}
\hline Table 1: Age distribution in smokers & & \\
\hline Age (yrs) & Frequency & Percentage \\
$21-30$ & 1 & $0.9 \%$ \\
$31-40$ & 10 & $9.3 \%$ \\
$41-50$ & 34 & $31.5 \%$ \\
$51-60$ & 36 & $33.3 \%$ \\
$61-70$ & 25 & $23.1 \%$ \\
$>70$ & 2 & $1.9 \%$ \\
\hline Total & 108 & $100.0 \%$ \\
\hline
\end{tabular}

The study group consisted of 108 subjects of which 80 (74.1\%) were males and $28(25.9 \%)$ were females. Ten $(90.9 \%)$ out of 11 subjects in the age group of 21-40 yrs were males. Out of 2 subjects in the age group of $>70 \mathrm{yrs}$, one $(50 \%)$ was male and $1(50 \%)$ was female.

Out of 108 study subjects, 80 (74.1\%) were males and 28 $(25.9 \%)$ were females.

Killip class is not applicable to 13 (12\%) study groups as they presented with Unstable Angina with ECG changes. Killip class 1 was most common presentation (67.6\%) in smokers. Killip class 4 patients were not included in the study.

Majority of patients (98\%) presented with Sinus Rhythm \& 2 $(1.9 \%)$ study subjects were presented with junctional rhythm which was exclusively seen in inferior wall STEMI study subjects.

28 patients (25.9\%) had LV dysfunction with $\mathrm{EF}<50 \%$ by echocardiography. 80 patients $(74.1 \%)$ had normal LV function. The mean EF was $55.56+/-10.16 \%$. The median $\mathrm{EF}$ was $56.5 \%$.

$48(44.4 \%)$ patients presented with Anterior wall STEMI which was the most common presentation of ACS in Smokers followed by inferior wall MI (34.3\%). Only 2 (1.9\%) patients were presented with high lateral / true posterior wall STEMI.

\section{Dominant System in smokers}

Out of 108 study subjects, RCA was dominant in 93 (86.1\%) patients, LCX was dominant in $12(12 \%)$ patients. Both RCA and LCX were codominant in $3(2.8 \%)$ patients. RCA dominance was statistically significant with $\mathrm{P}$ value $<0.05$ when compared with LCX dominance.

LAD was type 3 in 100 (92.6\%) patients and type 4 in 8 (7.4\%) patients out of 108 study subjects.LAD type 3 was statistically significant with $\mathrm{P}$ value $<0.05$ when compared with LAD type 4.

Number of vessels involved

- Normal coronaries: 7 (6.48\%)

- Single vessel disease: 49 (45.37\%)
- Double vessel disease: $26(24.07 \%)$

- Triple vessel disease: 19 (17.59\%)

- Double vessel disease with LMCA involvement: 3 $(2.77 \%)$

- Triple vessel disease with LMCA involvement: 4 (3.70\%)

Statistically, there was no significance difference between males and females with respect to number of vessels involved.

\section{Length of the LAD stenosis in smokers}

Out of 108 study subjects, LAD was normal in 29 (26.9\%), length of lesion was discrete in $51(47.2 \%)$, diffuse / tubular in $18(16.7 \%$ \& total cut off in $10(9.3 \%)$.

Out of 108 study patients, LMCA was normal in 100 (92.6\%), distal LMCA was involved in $7(6.48 \%)$ patients, out of 7 patients, distal LMCA was significantly involved (LMCA stenosis $>/=50 \%$ ) in $6(5.55 \%)$ patients. Proximal LMCA was seen in only $1(0.9 \%)$ patient out of 108 study subjects.

Out of 108 patients, LAD was normal in $29(26.9 \%)$ patients, location of lesion was ostial in $9(8.3 \%)$, proximal in 23 $(21.3 \%)$, mid in $33(30.6 \%)$, distal in $5(5.5 \%)$, multiple in 9 $(8.3 \%)$ patients. Out of 108 patients, LCX was normal in 66 $(61.6 \%)$. Location of lesion was ostial in 7(8.3\%), proximal in $9(8.3 \%)$, mid in $19(17.6 \%)$, distal in $4(3.7 \%)$, multiple in $3(2.8 \%)$. Out of 108 patients, RCA was normal in $32(29.6 \%)$, location of lesion was ostial in $3(2.8 \%)$, proximal in 24 $(22.2 \%)$, mid in $39(36.1 \%)$, distal in $10(9.2 \%)$.

SVD (Single vessel disease); DVD (Double vessel disease); TVD (Triple vessel disease); Normal vessels (Normal coronary arteries); CAG (Coronary angiography); NS (nonsignificant)

Single vessel disease was the most common CAG diagnosis in both the smokers and non-smokers ( $45.3 \%$ versus $51 \%$, $\mathrm{p}>0.1$, Non-significant).

Double vessel disease, even though not statistically significant, was more commonly encountered in smokers when compared to non-smokers ( $26.8 \%$ versus $18 \%, \mathrm{p}>0.1$, Not significant).

Triple vessel disease was equally encountered in both smokers and non-smokers $(21.1 \%$ versus $23 \%, \mathrm{p}>0.1$,Not significant) 
Table 2: Sex distribution in smokers

\begin{tabular}{lll}
\hline Variables & Frequency & Percentage \\
F & 28 & $25.9 \%$ \\
M & 80 & $74.1 \%$ \\
Total & 108 & $100.0 \%$ \\
\hline
\end{tabular}

Table 3: Killip class at the time of presentation in smokers

\begin{tabular}{lll}
\hline Killip Class & Frequency & Percentage \\
0 & 13 & $12.0 \%$ \\
1 & 73 & $67.8 \%$ \\
2 & 20 & $18.5 \%$ \\
3 & 2 & $2.7 \%$ \\
Total & 108 & $100 \%$ \\
\hline
\end{tabular}

Table 4: Rhythm at time of presentation in smokers

\begin{tabular}{lll}
\hline Rhyyhm & Frequency & Percentage \\
Junctional & 2 & $1.9 \%$ \\
NSR & 106 & $98.1 \%$ \\
Total & 108 & $100.0 \%$ \\
\hline
\end{tabular}

Table 5: Percentage of patients with and without $L V$ dysfunction (Ejection fraction) in smokers

\begin{tabular}{lll}
\hline EF & Frequency & Percentage \\
$<50$ & 28 & $25.9 \%$ \\
$>50$ & 80 & $74.1 \%$ \\
Total & 108 & $100.0 \%$ \\
\hline
\end{tabular}

Table 6: Type of Acute coronary syndrome at presentation in smokers

\begin{tabular}{lll}
\hline Type of Acute coronary syndrome & Frequency & Percentage \\
\hline Inferir wall STEMI including RVMI & 37 & $34.3 \%$ \\
\hline Anterior wall STEMI & 48 & $44.4 \%$ \\
\hline UA WITH ECG CHANGES & 14 & $13.0 \%$ \\
High lateral STEMI & 2 & $1.9 \%$ \\
Anterior wall NSTEMI & 5 & $4.6 \%$ \\
True Posterior wall STEMI & 2 & $1.9 \%$ \\
\hline Total & 108 & $100.0 \%$ \\
\hline
\end{tabular}

Table 7: RCA dominance

\begin{tabular}{lll} 
RCA dominance & Frequency & Percentage \\
Dominant & 93 & $86.1 \%$ \\
non dominant & 12 & $11.1 \%$ \\
co dominant & 3 & $2.8 \%$ \\
Total & 108 & $100.0 \%$ \\
\hline
\end{tabular}




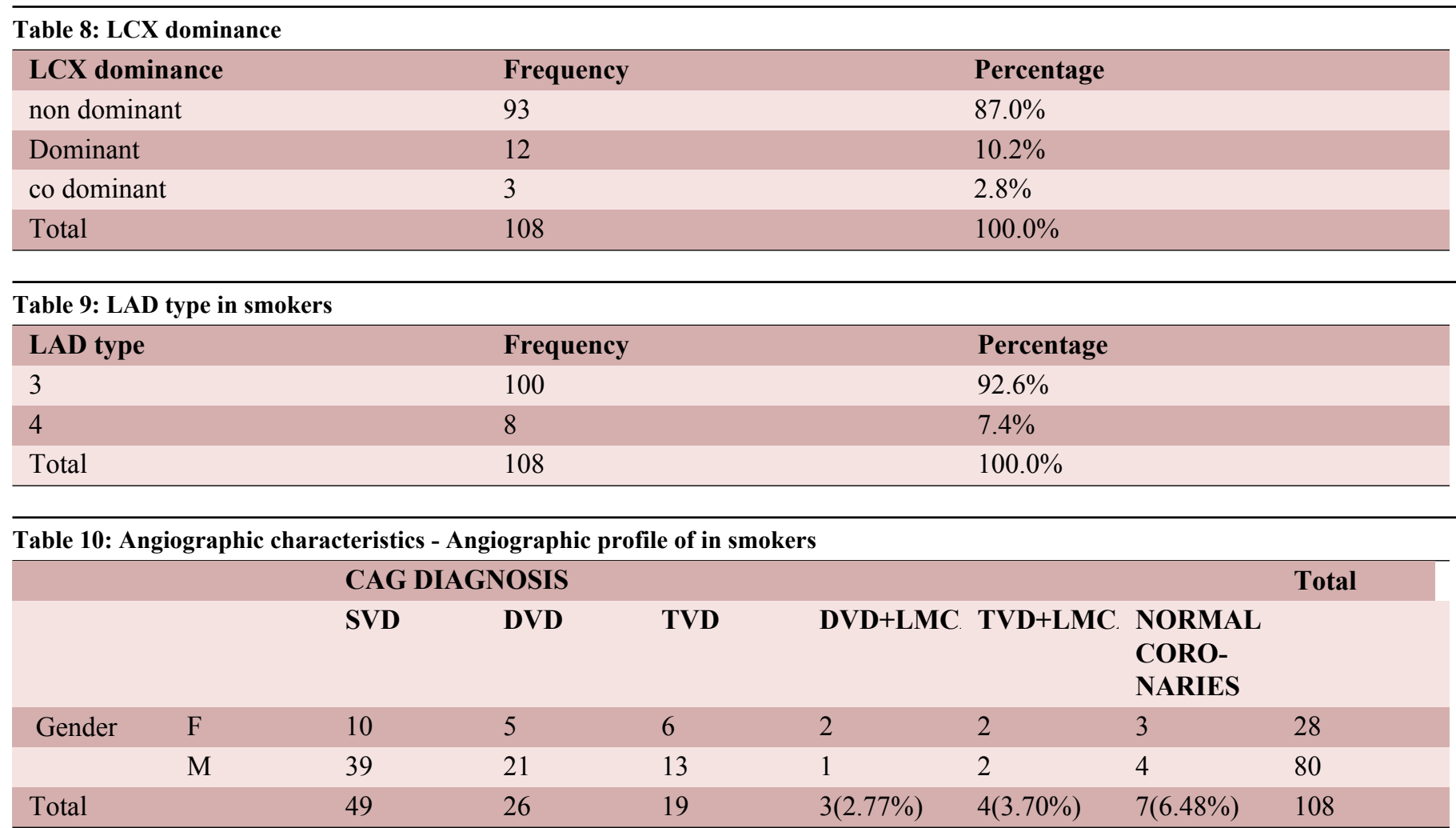

Chi square $=6.545, \mathrm{p}=0.682$ - Not significant

Table 11: LAD length of lesion

\begin{tabular}{lll}
\hline LAD length of lesion & Frequency & Percentage \\
Diffuse/tubular & 18 & $16.7 \%$ \\
Discrete & 51 & $47.2 \%$ \\
Normal & 29 & $26.9 \%$ \\
total cut off & 10 & $9.3 \%$ \\
Total & 108 & $100.0 \%$ \\
\hline
\end{tabular}

Table 12: LMCA stenosis ( $>/=30 \%$ diameter narrowing) involvement in smokers

\begin{tabular}{lll}
\hline LMCA status & Frequency & Percentage \\
Normal & 100 & $92.6 \%$ \\
\hline Distal LMCA 80\% & 1 & $0.9 \%$ \\
Distal LMCA 60\% & 5 & $4.6 \%$ \\
Distal LMCA 30\% & 1 & $0.9 \%$ \\
Proximal LMCA with ostium 60\% & 1 & $0.9 \%$ \\
Total & 108 & 100.0 \\
\hline
\end{tabular}

Table 13: Location of lesion in the involved artery in smokers

\begin{tabular}{llllllll} 
Artery & Normal & Ostial & Proximal & Mid & Distal & Multiple & Total \\
LAD & $29(26.9 \%)$ & $9(8.3 \%) 0)$ & $23(21.3 \%)$ & $33(30.6 \%)$ & $5(5.5 \%))$ & $9(8.3 \%)$ & 108 \\
LCX & $66(61.1 \%)$ & $7(6.5 \%)$ & $9(8.3 \%)$ & $19(17.6 \%)$ & $4(3.7 \%)$ & $3(2.8)$ & 108 \\
RCA & $32(29.6 \%)$ & $3(2.8 \%)$ & $24(22.2 \%)$ & $39(36.1 \%)$ & $10(9.2 \%)$ & $0(0 \%)$ & 108 \\
\hline
\end{tabular}




\begin{tabular}{llll}
\hline \multicolumn{4}{l}{ Table 14: Coronary angiographic diagnosis as the number of vessels involved } \\
\hline CAG diagnosis & Smokers & Non smokers & P value \\
SVD & $49(45.3 \%)$ & $51(51 \%)$ & $>0.1$ (NS) \\
DVD & $29(26.8 \%)$ & $18(18 \%)$ & $>0.1$ (NS) \\
TVD & $23(21.2 \%)$ & $23(23 \%)$ & $>0.1$ (NS) \\
Normal vessels & $7(6.7 \%)$ & $8(8 \%)$ & $>0.1$ (NS) \\
Total & $108(100 \%)$ & $100(100 \%)$ & \\
\hline
\end{tabular}

No statistically significant difference was seen with respect to the Normal coronary arteries as $\mathrm{CAG}$ diagnosis between smokers and non-smokers (6.7\% versus $8 \%, \mathrm{p}>0.1$, Not significant).

Out of 108 study subjects in the smokers group, LMCA stenosis ( $>30 \%$ diameter stenosis) was present in $8(7.4 \%)$ subjects. Out of 100 study subjects in the non-smoker group, LMCA stenosis was present in $10(10 \%)$ subjects. No statistically significance difference was seen with respect to LMCA stenosis in the study groups $(7.4 \%$ versus $10 \%$, $\mathrm{p}>0.1$, No significant difference). The LMCA stenosis was often encountered in Diabetic study subjects in both study groups $(70.4 \%$ in diabetics, $29.6 \%$ in non-diabetics $<0.001$, statistically significant difference).

LAD (Left anterior descending artery); Absent (mid and distal LAD stenosis+Normal LAD); NS (Non significant)

Out of 108 study subjects in the smokers group, proximal LAD stenosis was present in 32(29.6\%) study subjects. Out of 100 study subjects in the non smokers group, proximal LAD stenosis was present in $25(25 \%)$ subjects.

No statistically significant difference was seen with respect to proximal LAD stenosis ( $>/=50 \%$ stenosis) between smokers and non-smokers ( $29.6 \%$ versus $25 \%, \mathrm{p}>0.1$,Non-significant).

\section{Baseline characters and angiographic profile in smokers}

\section{Age Vs Angiographic profile in smokers}

Normal coronaries and SVD, DVD, TVD vs Age Chi square $=7.96, \mathrm{P}$ value $=0.05$ significant Out of 108 study subjects with normal coronaries, 7 (100\%) patients were less than 50yrs age group. Out of 49 patients with SVD, 20 (40.8\%) patients were up to the age of 50 years and remaining 29 $(59.1 \%)$ were more than 50 years. Out of 26 patients with DVD, $11(42.3 \%)$ were upto the age of 50 years and remaining $15(57.7 \%)$ were more than 50 years. Out of 19 patients with TVD, $6(31.5 \%)$ patients were up to the age group of 50 years and remaining $13(68.5 \%)$ were more 50 years .Out of 7 patients with LMCA involvement,6 (85.7\%) patients were more than 50 years and remaining $1(14.3 \%)$ patient was less than 50 years.

A significantly higher proportion of patients $(100 \%)$ up to 50 years of age have normal coronaries (No vessels involved). A Statistically significant higher proportion of patients (85.7\%) with age more than 50 yrs have LMCA involvement (Chi square $-6.96, \mathrm{P}=0.005)$.

\section{Hypertension Vs Angiographic profile in smokers}

Out of the 7 patients with normal coronaries, 5 (71.5\%) patients were non hypertensives and remaining 2 (28.5\%) patients were hypertensives. Out of 48patients with SVD, $21(42.9 \%)$ patients were hypertensives and remaining 28 (57.1\%) patients were non hypertensives. Out of 26 patients with DVD,15 (57.7\%) patients were hypertensives and remaining $11(42.3 \%)$ patients were non hypertensives. Out of 19 patients with TVD,13 (69.5\%) patients were hypertensives and remaining $6(31.5 \%)$ patients were non hypertensive. Out of 7 patients with LMCA involvement,5 (71.5\%) patients were hypertensive and remaining $2(28.5 \%)$ patients were non hypertensive. Coronary arteries are significantly involved in Hypertensive patients.

\section{TVD, LMCA vs Hypertension (Chi square - 17.5, p $<0.001$ significant)}

Among study subjects with coronary artery involvement seen, there was a statistically significant difference between hypertensives and Non hypertensives with respect to TVD / LMCA involvement.

\section{Diabetes mellitus Vs Angiographic profile in smokers}

Normal coronaries Vs SVD, DVD, TVD, LMCA - (Chi square $=0.71, \mathrm{P}=0.4$, not significant.) Out of 7 patients with normal coronaries, $3(42.9 \%)$ patients were Diabetics and remaining $4(57.1 \%)$ were non diabetics. Out of 49 patients with SVD, 7 (14.3\%) patients were Diabetics and remaining were Non Diabetics. Diabetes was significantly associated with TVD / LMCA involvement when compared to Non Diabetes. (Chi square $=9.67, \mathrm{p}<0.005$, significant). Coronaries are significantly involved in a higher proportion of diabetic study subjects.

Combined form $(64.8 \%)$ with $\mathrm{p}$ value $<0.001$, was the most common form of tobacco use in smokers. Heavy smoking $(2.9 \%)$ was least common form of tobacco tobacco use. 
Table 15: Prevalence of Left main coronary artery stenosis ( $>30 \%$ diameter narrowing) in the study subjects

\begin{tabular}{llll}
\hline LMCA & Smokers & Non smokers & P value \\
Normal & $100(92.6 \%)$ & $90(90 \%)$ & \\
Stenosis & $8(7.4 \%)$ & $10(10)$ & $>0.1(\mathrm{NS})$ \\
Total & $100(100 \%)$ & $100(100 \%)$ & \\
\hline
\end{tabular}

LMCA (Left main coronary artery); NS (Non-significant)

Table 16: Prevalence of the Proximal Left anterior descending coronary artery stenosis $(>/=50 \%$ diameter narrowing $)$ in the study subjects.

\begin{tabular}{llll}
\hline Proximal LAD stenosis & Smokers & Non smokers & P value \\
Present & $32(29.6 \%)$ & $25(25 \%)$ & $>0.1($ NS) \\
Absent & $76(69.4 \%)$ & $75(75 \%)$ & \\
Total & $108(100 \%)$ & $100(100 \%)$ & \\
\hline
\end{tabular}

Table 17: Association between age and number of vessels involved

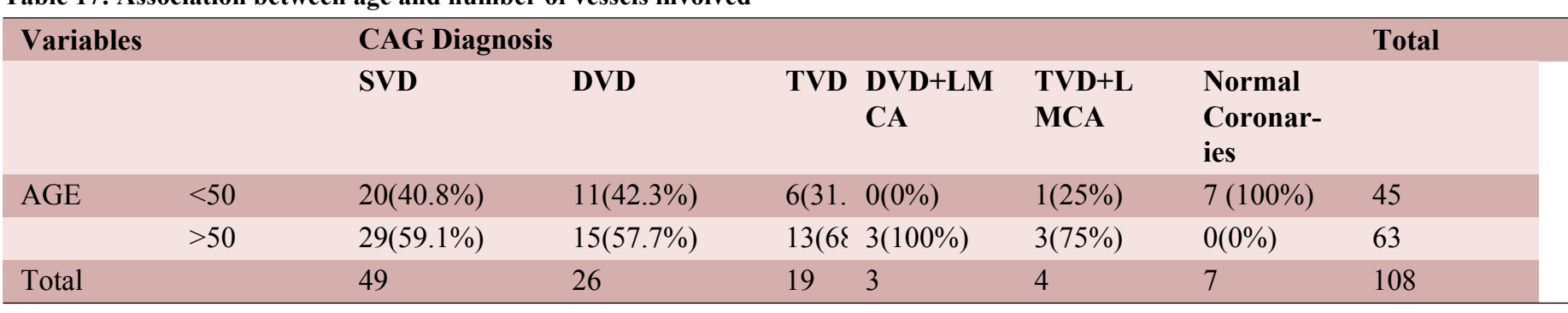

Table 18: Hypertension Vs number of vessels involved

\begin{tabular}{|llllllll}
\hline Variables & & \multicolumn{2}{l}{ CAD Diagnosis } & TVD & LMCA & $\begin{array}{l}\text { Normal } \\
\text { Coronaries }\end{array}$ & Total \\
& & SVD & DVD & TVD & \\
\hline HTN & No & $28(57.1 \%)$ & $11(42.3 \%)$ & $6(31.5 \%)$ & $2(28.5 \%)$ & $5(71.5 \%)$ & 52 \\
\hline & Yes & $21(42.9 \%)$ & $15(57.7 \%)$ & $13(69.5 \%$ & $5(71.5 \%)$ & $2(28.5 \%)$ & 56 \\
Total & & 49 & 26 & 19 & 7 & 7 & 108 \\
\hline
\end{tabular}

Normal coronaries and SVD, DVD, TVD, LMCA vs Hypertension Chi square $=19.7, \mathrm{p}<0.001$

Table 19: Diabetes mellitus vs. no of vessels involved

\begin{tabular}{llllllll} 
Variables & & CAG Diagnosis & Total & \multicolumn{2}{c}{ Normal } \\
& & SVD & DVD & TVD & LMCA & $\begin{array}{l}\text { Noronaries } \\
\text { Coron }\end{array}$ \\
\hline DM & No & $42(85.7 \%)$ & $22(84.6 \%)$ & $12(63.1 \%)$ & $2(28.6 \%)$ & $4(57.1 \%)$ & 82 \\
& Yes & $7(14.3 \%)$ & $4(15.4 \%)$ & $7(36.9 \%)$ & $5(71.4 \%)$ & $3(42.9 \%)$ & 26 \\
Total & & 49 & 26 & 19 & 7 & 7 & 108 \\
\hline
\end{tabular}

Table 20: Form of Smoking in smokers

\begin{tabular}{ll}
\hline $\begin{array}{l}\text { 1.Tobacco Chewing including pan,gutca }+ \text { Cigaratte smoking including Chutta } \\
\text { (Combined form) }\end{array}$ & $70(64.8 \%)$ \\
2.Cigaratte Smoking with smoking index $<10$ pack years & $5(4.6 \%)$ \\
3.Cigaratte Smoking with smoking index $>/=10$ and $<20$ pack years & $30(27.7 \%)$ \\
4.Cigaratte Smoking with smoking index $>/=20$ pack years & $3(2.9 \%)$ \\
\hline
\end{tabular}




\section{Discussion}

In the present study, the majority of patients in the smoking group were males $(74.1 \%)$ when compared to females but majority of patients in the non-smoking group were females $(61 \%)$. The mean age of the patients in the smoking group was 53.52years and in the non-smokers, mean age was 59.48years. In the present study, smoking reduced the age at which the first coronary event occurred by approximately seven years.

Majority of the study subjects reached ICCU with acute myocardial infarction as acute coronary event but Unstable angina with ECG changes was often encountered in the non smokers group. The smokers had a greater prevalence of infarction and less unstable angina, probably related to younger age and due to the procoagulant effect of tobacco.

In smokers, anterior wall STEMI (44.1\%) was the most common presentation followed by acute inferior wall STEMI $(34.3 \%) .{ }^{[13-15]}$

A stronger association was seen between smoking and obesity and a weaker one with Diabetes mellitus. Diabetes mellitus was more common in the non smoker group. Hypertension had no association with smoking.

Smokers had a relatively greater number of associated risk factors than non smokers. The smokers had more obesity than non smokers.

Majority of the patients (74.1\%) in the study group had EF $>50 \%$ with mean EF was $55.56 \%$.

The Combined form of Tobacco $(64.8 \%)$ use was the most commom in the smokers group and difficulty to measure smoking index in all smoking subjects and heavy smoking (smoking index $>/=20$ pack years) was less common (3.29\%). Present study included patients with current smoking and Ex smoking within 6 monthes of cessation with all forms of smoking. ${ }^{[16-18]}$

Majority of the study subjects in smokers had the dominant Right coronary artery and the Rigyt coronary artery was codominant in $2.8 \%$ in smokers. Type $3 \mathrm{LAD}$ was seen in majority of the smokers (92.6\%).

Single vessel disease was the most common CAG diagnosis followed by Double vessel disease was in both smokers and non-smokers.

Significant LMCA $(>/=30 \%$ diameter stenosis) involvement was often seen in Diabetic patients as an additional risk factor in smokers. There was no significant difference between males and females with respect to number of vessels involved in study population.

LAD was the artery predominantly involved in smokers .Among the involved coronaries, discrete lesions were predominantly seen when compared to long/diffuse lesions in each of the individual vessels in smokers group compared to non-smokers. There was no statistical difference with respect to proximal $\mathrm{LAD}$ involvement $(>/=40 \%$ diameter stenosis $)$ between smokers and non-smokers. ${ }^{[19]}$

An analysis between the baseline characteristics and the angiographic profile in smokers was suggestive of the following features: Significant coronary artery involvement (diameter stenosis $>/=40 \%$ of the reference vessel ) was seen in a higher proportion of patients who were older than 50 years, in a higher proportion of patients who were diabetics, hypertensive \& obese patients in addition to the smoking.

The LMCA was involved in majority of patients older than $50 y e a r s$ and often seen in Diabetics in all study subjects.

GRACE is a multinational observational registry and compared smokers Vs non-smokers in acute coronary syndrome and based on 19,325 patients aged at least 18 years admitted for acute coronary syndromes.

GRACE study showed that Smokers were more frequently diagnosed with STEMI (46.0\%) than former smokers (27.4\%) and non- smokers $(30.2 \%)(\mathrm{P}<0.001)$. Smokers were mostly men, were younger than non-smokers across the three acute coronary syndrome groups. ${ }^{[15]}$

In the study, published in The Indian hert journal in October 2005, Clinical Outcome and Angiographic Profile of Acute Myocardial Infarction in Smokers were studied. The baseline characters included All smokers admitted with acute MI were males and their mean age was $48 \pm 11.6$ years. $39 \%$ of patients were diabetics, $36 \%$ of patients were hypertensives and $26 \%$ had a family history of CAD. $71 \%$ of patients were smokers and $61 \%$ had anterior wall MI, $36 \%$ had inferior wall MI and $3 \%$ had true posterior wall MI. $81 \%$ received thrombolytic therapy with a window period of $2.1 \pm 1.9$ hours. $59 \%$ had normal LV systolic function and $22 \%$ had LV dysfunction (mean EF $42 \pm 4 \%$ ). In coronary angiogram, single vessel disease was seen in $42 \%$ of patients and multi vessel disease in $37 \%$ of patients. Recanalised coronary arteries with no significant flow limiting disease were seen in $21 \%$ of patients. Multi vessel disease was seen in patients with diabetes or newly detected diabetics. Multi vessel disease was higher in patients with LV dysfunction $(68 \%)$ whereas recenalised coronaries after thrombolytic therapy was $9 \% .{ }^{[18-20]}$

In comparison with above two studies, present study showed younger age of presentation of acute coronary syndrome in smokers, often seen in males, with mean age of 53.52 years and smokers had more obesity and less diabetes mellitus when compared to non-smokers. Single vessel disease, LAD involvement were seen in a higher percentage of patients in the present study subjects. ${ }^{20]}$ 


\section{Limitations}

1. More critically ill patients were excluded like ACS patients with cardiogenic shock.

2. Difficulty to quantify the smoking parameters with respect to acute coronary syndrome.

\section{Conclusion}

1. Smokers presented with more Acute infarctions and less Unstable angina compared with non-smokers $(\mathrm{P}<0001)$.

2. Anterior wall STEMI was the most common acute coronary syndrome among smokers.

3. Single vessel disease wasthe most common CAG diagnosis in both smokers and non-smokers.

4. LMCA involvement was commonly encountered in both smokers and non-smokers who had diabetes mellitus.

\section{Acknowledgment}

The author thankful to Department of cardiology, Katuri Medical College \& Hospital for providing all the facilities to carry out this work.

\section{References}

1. Murray CJ, Lopez AD. Mortality by cause for eight regions of the world: Global Burden of Disease Study. Lancet. 1997;349(9061):1269-1276. Available from: https://dx.doi. org/10.1016/s0140-6736(96)07493-4.

2. Ockene IS, Miller NH. Cigarette Smoking, Cardiovascular Disease, and Stroke. Circulation. 1997;96(9):3243-3247. Available from: https://dx.doi.org/10.1161/01.cir.96.9.3243.

3. He J, Ogden LG, Bazzano LA, Vupputuri S, Loria C, Whelton PK. Risk Factors for Congestive Heart Failure in US Men and Women. Arch Intern Med. 2001;161(7):996-996. Available from: https://dx.doi.org/10.1001/archinte.161.7.996.

4. Muscat JE, Harris RE, Haley NJ, Wynder EL. Cigarette smoking and plasma cholesterol. Am Heart J. 1991;121(1):141-147. Available from: https://dx.doi.org/10.1016/0002-8703(91) 90967-m.

5. Hung J, Lam JYT, Lacoste L, Letchacovski G. Cigarette Smoking Acutely Increases Platelet Thrombus Formation in Patients With Coronary Artery Disease Taking Aspirin. Circulation. 1995;92(9):2432-2436. Available from: https: //dx.doi.org/10.1161/01.cir.92.9.2432.

6. Campisi R, Czernin J, Schöder H, Sayre JW, Marengo FD, Phelps ME, et al. Effects of Long-term Smoking on Myocardial Blood Flow, Coronary Vasomotion, and Vasodilator Capacity. Circulation. 1998;98(2):119-125. Available from: https://dx. doi.org/10.1161/01.cir.98.2.119.
7. Fusegawa Y, Goto S, Handa S, Kawada T, Ando Y. Platelet Spontaneous Aggregation in Platelet-Rich Plasma Is Increased in Habitual Smokers. Thrombosis Res. 1999;93(6):271278. Available from: https://dx.doi.org/10.1016/s00493848(98)00184-4.

8. Jha P, Peto R. Global Effects of Smoking, of Quitting, and of Taxing Tobacco. N Engl J Med. 2014;370:60-68. https:/ /dx.doi.org/10.1056/NEJMra1308383. Available from: https: //dx.doi.org/10.1056/NEJMra1308383.

9. Roberts NJ, Kerr SM, Smith SMS. Behavioral Interventions Associated with Smoking Cessation in the Treatment of Tobacco Use. Health Serv Insights. 2013;6:79-85. Available from: https://dx.doi.org/10.4137/FHSI.S11092.

10. Singh V, Gupta R. Prevalence of Tobacco Use And Awareness Of Risks Among School Children In Jaipur. J Assoc Physicians India. 2006;54:609-612.

11. Biswas PK, Dasbiswas A, Roy S, Roy D, Biswas A, Chatterjee SS. Risk factors and angiographic profile of coronary artery disease in young. J Indian Med Assoc. 1995;93(03):90-92.

12. Ahmad T, Alam MB, Khan A. Study on Risk Factors and Pattern of Coronary Artery Involvement inYoung Acute Coronary Syndrome Patients. Bangladesh Heart J. 2017;32(1):40-44.

13. Kanitz MG, Giovannucci SJ, Jones JS, Mott M. Myocardial infarction in young adults: Risk factors and clinical features. J Emerg Med. 1996;14(2):139-145. Available from: https: //dx.doi.org/10.1016/0736-4679(95)02089-6.

14. Thun MJ, Carter BD, Feskanich D, Freedman ND, Prentice R, Lopez AD, et al. 50-Year Trends in Smoking-Related Mortality in the United States. N Engl J Med. 2013;368(4):351-364. Available from: https://dx.doi.org/10.1056/nejmsa1211127.

15. Ambrose JA, Barua RS. The pathophysiology of cigarette smoking and cardiovascular disease. J Am Coll Cardiol. 2004;43(10):1731-1737. Available from: https://dx.doi.org/10. 1016/j.jacc.2003.12.047.

16. Rigotti NA, Clair C, Munafò MR, Stead LF. Interventions for smoking cessation in hospitalised patients. Cochrane Database Syst Rev. 2012;5:1837-1837. Available from: https://dx.doi. org/10.1002/14651858.cd001837.pub3.

17. Aune E, Roislien J, Mathisen M. The "smoker's paradox" inpatients with acute coronary syndrome: a systematic review. BMC Med. 2011;9:97-101.

18. Rosenberg L, Palmer JR, Shapiro S. Decline in the Risk of Myocardial Infarction among Women Who Stop Smoking. N Eng J Med. 1990;322(4):213-217. Available from: https://dx. doi.org/10.1056/nejm199001253220401.

19. Rosenberg L, Kaufman DW, Helmrich SP, Shapiro S. The Risk of Myocardial Infarction after Quitting Smoking in Men under 55 Years of Age. $\mathrm{N}$ Eng J Med. 1985;313(24):1511-1514. Available from: https://dx.doi.org/ 10.1056/nejm198512123132404.

20. Patrick DL, Cheadle A, Thompson DC, Diehr P, Koepsell T, Kinne $\mathrm{S}$. The validity of self-reported smoking: a review and meta-analysis. Am J Public Health. 1994;84(7):1086-1093. Available from: https://dx.doi.org/10.2105/ajph.84.7.1086. 
Copyright: (C) the author(s), 2020. It is an open-access article distributed under the terms of the Creative Commons Attribution License (CC BY 4.0), which permits authors to retain ownership of the copyright for their content, and allow anyone to download, reuse, reprint, modify, distribute and/or copy the content as long as the original authors and source are cited.

How to cite this article: Korrapati H, Reddy BVN, Chegireddy S. A Study on Angiographic profile of Acute Coronary Syndrome in Smokers. Acad. J Med. 2020;3(1):32-41.

DOI: dx.doi.org/10.47008/ajm.2020.3.1.8

Source of Support: Nil, Conflict of Interest: None declared. 